\title{
A RÁCK FOR USE IN PRECIPITATION TESTS
}

\author{
BY \\ I. N. ORPWOOD PRICE \\ From the Venereal Disease Reference Laboratory, London
}

Those who are engaged in the serological diagnosis of syphilis and who employ precipitation reactions involving the use of a shaking machine would no doubt be grateful if the noise made by tubes in a metal rack whilst this is being shaken could be eliminated. To this end a special rack has been designed.

\section{The Apparatus}

It consists of a block of wood $9 \frac{3}{4}$ in. by $3 \frac{3}{4}$ in. by 2 in. into which have been drilled forty-eight holes of $\frac{1}{2}$ in. diameter in four rows of twelve.
The top of the wooden rack is covered by a thin sheet of white plastic, drilled with holes of a similar size and position to those on the wooden block. Fixation on to the wood is secured by glue and six brass screws. The plastic top has the advantage that it can be written on with a grease pencil without being heated, and it is easily cleaned by one or two rubs of a duster. The noise of rattling tubes when the shaking takes place is, for practical purposes, eliminated, A second advantage of this rack is that its shape is not distorted after use. Metal racks suffer from this defect.

These racks have been made for me by The "Visijar" Laboratory Supply Company Limited, 36, Prince of Wales Road, Sutton, Surrey, and are priced at $12 s$. 6d. each. 